\title{
The Role of Personality Pattern Behaviors in Risk Behaviors of High School Students
}

\author{
Roya Samadypoor, ${ }^{1}$ and Bahman Kord Tamini ${ }^{1, *}$ \\ ${ }^{1}$ Department of Psychology, University of Sistan and Baluchestan, Zahedan, IR Iran \\ "Corresponding author: Bahman Kord Tamini, Department of Psychology, University of Sistan and Baluchestan, Zahedan, IR Iran. Tel: +98-5431136768, Fax: +98-5433416120, \\ E-mail: bahman_kord@ped.usb.ac.ir
}

Received 2016 January 13; Revised 2016 September 27; Accepted 2016 October 15.

\begin{abstract}
Background: There are many risky behaviors that threat adolescents and must receive specific attention. Research has shown that personality pattern behaviors have a significant relationship with risky behaviors.

Objectives: The objective of this study was to clarify the role of personality pattern behaviors in risky behaviors of high school students in Chabahar city.

Patients and Methods: Three hundred high school students from Chabahar city were selected at random for this study and filled Type A and B pattern behavior profile and Type D personality and sensation seeking (Type T Personality) questionnaires.

Results: To analyze the data, Pearson correlation coefficient and multiple stepwise regression were applied. Results revealed that type of sensation seeking (Type T personality) and Type A behavior pattern were significantly correlated with risky behaviors. Type D personality had a significant negative correlation with risky behaviors. Type B behavior pattern was not significantly correlated with risky behaviors. The results of multiple stepwise regressions demonstrated that type A behavior pattern, type $\mathrm{D}$, and type $\mathrm{T}$ personality explained $11.4 \%$ of the variance in risky behaviors, respectively. Type T and type A personality was a positive and type D personality was a negative predictor of risky behaviors.

Conclusions: In conclusion personality pattern behaviors had a unique role in risky behaviors of high school students in Chabahar city and the training and education organization should identify their personality patterns to prevent risky behaviors among them.
\end{abstract}

Keywords: Personality Pattern, Risk Behaviors, Students

\section{Background}

Youth and adolescences are the human resource of every society and they consist of the majority population of developing countries, especially in Iran. "Adolescence is a critical period for the development of healthy behaviors and lifestyles" (1) and adolescents are vulnerable to environmental changes, because their personality does not perform well and they are trying to achieve an integrated identity for themselves. There are many risky behaviors that threat adolescents and it is needed to pay specific attention to such behaviors. The centers for disease control and prevention (CDC) has declared six health risky behaviors that are especially salient for the development of optimal health. These six risky behaviors are as follows: (a) behaviors that contribute to unintentional injuries and violence, (b) tobacco use, (c)alcohol consumption and other drug use, (d) sexual behaviors that contribute to unwilling pregnancy and sexually transmitted diseases, (e) unhealthy dietary behaviors, and (f) physical inactivity (2). Researchers believe that high-risk behaviors increase the likelihood of destructive physical, psychological and social consequences for the individual. These risky behav- iors are evident among adolescents, who are extremely dependents on each other and imitate their peers' behavior patterns. Moreover, sexual risk-taking has been recently highlighted as a reason for unwilling pregnancy, infectious disease and human immunodeficiency virus (HIV) $(3,4)$. Personality is a very important variable in psychology and many researchers have concisely been focused on this variable and they have provided definitions for it. In accordance to Kazdin (5), "personality refers to individual differences in characteristic patterns of thinking, feeling and behaving. The study of personality focuses on two broad areas: one is understanding individual differences in particular personality characteristics, such as sociability or irritability. The other is understanding how the various parts of a person come together as a whole". The psychological classification of different types of individuals is considered as personality types. There is a distinction between personality types and personality traits, with the latter embodying a smaller grouping of behavioral tendencies. Types sometimes refer to qualitative differences between people, whereas traits might be construed as quantitative differences (6). There are two famous personality types that are identified as Type A and Type B personality 
behavior theory. This theory emphasizes that Type A personalities are impatient, achievement-oriented and in contrast Type B personalities are easy-going and relaxed individuals. According to this theory Type A individuals were more at risk for coronary heart disease, but empirical research has not supported this claim (7). Moreover, Denollet in 1996 proposed Type D personality that was originally identified through observations of patients with coronary heart diseases (CHD) (8). This personality type is identified with two personality traits: negative affectivity (NA) and social inhibition (SI) (9). Studies have revealed that Type D personality patients experience increased levels of depressive symptoms $(10,11)$. Research reveals that Type D personality was associated with anxiety and increased depressive symptoms at baseline and moreover, heart failure and type D personality were related to poorer health status (12). Type T personality or sensation-seeking personality is one of the main personality types, which plays an important role in risk behaviors. This type of personality has been recognized as a personality dimension that refers to individual differences in stimulation seeking, excitement seeking, thrill seeking, arousal seeking and risk taking (13).

Studies have shown that personality types have a very important role in risky behaviors, for instance, Perry and Baldwin (14) showed that Type A personality was significantly related to more traffic accidents, greater frequency of breaking traffic laws, higher impatience when driving, more displays of aggression on the road, and engaging in more risky driving behaviors. Type A drivers reported being involved in significantly more motor vehicle accidents and reported displaying more aggression on the road in comparison to Type B personality. Studies demonstrated that Type B individuals engaged in more preventive, and fewer risk-related behaviors under high stress, than those who were self-reported as Type A (15). In a study Drabek, Merecz and Moscicka (16) showed that tendency to express an aggressive reaction towards violent behavior of others was positively correlated with a high level of trait-anxiety and Type A behavior pattern, and submissive reactions to violence with a high level of trait-anxiety and Type B behavior pattern, whereas tendency to express assertive reaction when being attacked was related to a low level of trait-anxiety and Type $B$ behavior pattern. Researchers also have found that the hostility component of Type A personality is the only significant risk factor. Thus, it is a high level of expressed anger and hostility, not the other elements of Type A behavior, which constitute the problem (17). Individuals, who were classified as Type A pattern, had ratings lower on trustful, controlled, and timid, and higher on aggressive, distrustful and uncontrolled behaviors than Type B pattern (18). Lombardo and Carreno (19) demonstrated that Type As' alveolar carbon monoxide (COa) levels were higher than Type Bs', and Jenkins Activity Survey scores were correlated with $\mathrm{COa}$ and their findings revealed that Type As and Type Bs did not differ in number of puffs taken or puff volume, but Type As' inhalation duration was 70\% longer than Type Bs'. They discussed that due to increased smoke exposure, Type A smokers may also be at greater risk of cancer and lung disease than Type B smokers.

Studies have shown that Type-D personality was uniquely associated with suicidal ideation (20). The results of a cross-sectional study revealed that Type D personality was associated with psychological distress and an unhealthy lifestyle in Icelandic cardiac patients and moreover, Type D patients were also more likely to smoke during the follow-up and to use antidepressants and sleeping pills compared to non-Type Ds (21). A study conducted by Bruce, Curren and Williams (22), identified that there was a positive relationship between Type $D$ personality and alcohol dependence in the general population. Results have also shown that this relationship was mediated by coping and conformity drinking motives. Studies have shown that Type D personality is a vulnerability factor that may help identify subgroups of cancer survivors, who are at an increased risk for comorbidity burden and increased health care utilization (23). Japanese researchers demonstrated that Type D personality was at four to five times the risk of psychological distress, and twice the risk of poor self-rated health and moreover, Type D personality was associated with adverse health status among Japanese elderly people in terms of mental and physical risk (24).

Type $\mathrm{T}$ personality individuals are more prone to risky behaviors, for instance, in a study by Jones, Chryssanthakis and Groom (25), it was found that sensation seeking (Type $\mathrm{T}$ personality), urgency and lack of premeditation were related to different motives for drinking, and also showed dissociable relationships between the consumption of specific types of alcohol (beer, wine and spirits) and the tendency to engage in risky behaviors associated with alcohol consumption. Studies revealed direct effects of peers' sensation seeking on adolescents' own use of both marijuana and alcohol two years later and the individual's own sensation seeking had an indirect effect on drug use two years later (26). Sensation seeking was significantly associated with smoking and alcohol consumption (27). Evidences have shown that sensation seeking (Type T personality) has a relationship with driving speed, and this behavior is seen in both males and females. Those with high scores in sensation seeking are more likely to engage in speeding and moreover, results found that peer sensation seeking levels are predictive of drug use (28). Type T personality or high sensation seekers had multiple sexual partners and tended to engage in high-risk sexual behavior (29). Studies documented by Gullette and Lyons (30) 
showed that age, high score on sensation seeking and college alcohol problem scale, yet a low score on sexual compulsivity scale, was a significant predictor of HIV. Hampson et al. (31) revealed that initial level and growth of sensation seeking predicted membership in any smoker class versus nonsmokers. At age $20 / 21$, there was a positive association between smoking and hookah use for nonsmokers and experimenters in high school, whereas this association was not significant for stable regular smokers or rapid escalators. Sensation seeking, particularly disinhibition, was strongly associated with smoking among youth (32). Mccoul and Haslam (29) discussed that among heterosexuals, impulsivity and sexual sensation seeking personality variables were associated with frequency of unprotected sex but only sexual sensation seeking was associated with number of sex partners. Sexual sensation seeking also mediated the association between use of drugs other than alcohol and number of sex partners. Among homosexuals, no personality or substance use variables predicted highrisk sexual behavior.

\section{Objectives}

Research evidences around the world have shown that personality pattern behaviors have a dominant role in risky behaviors, and it is obvious that risky behaviors increase at an early age of adolescence and meanwhile personality pattern behaviors are constituted. Therefore, if there is no scientific training at present, adolescents are vulnerable against environmental changes and social demands. The Chabahar city is located in the southwest of Iran and is neighboring Pakistan, from which illegal drugs and opium is transited to Iran and adolescents (high school students) of this city are exposed to risky behaviors such as addiction, smoking, using illegal drugs, and alcohol consumption, and moreover, the traditional culture of this city is affected by other cultures and these effects lead to changes in adolescents behaviors, like unprotected sexual behaviors, and increase the risk of sexual disease transmission, especially HIV. The present study attempted to clarify the role of personality pattern behaviors in risky behaviors in high school students of Chabahar city. For this purpose, two questions were designed as fallows:

1. Do risky behaviors have a significant correlation with personality pattern behaviors?

2. How well do the four personality type patterns (Type A, B, D and T pattern behavior) predict risk behavior? How much variance in risky behavior scores could explain the scores on these four personality type patterns?

\section{Patients and Methods}

This study was correctional descriptive. The sample of this study consisted of 300 high school students that were selected at random. To perform this study, a permission letter was taken from the psychology department of Sistan and Baluchestan University to Training and Education Organization of Sistan and Baluchestan Province, and after obtaining the approval, the researcher was refereed to the Training and Education Organization of Chabahar branch. Before filling the questionnaires and scales, the high school students were assured that there were no correct or wrong responses on each item and were told that their personal information will be kept confidential and will be used for research purposes only.

\subsection{Instruments}

\subsubsection{Iranian Adolescents Risk Behavior Scale}

This scale was developed by Zade Mohammadi and Ahmadabadi (33) to assess the adolescents risky behaviors in the Iranian population. This scale consists of 39 items, which identify the vulnerability of adolescents in six dimensions of risky behaviors that are as fallows: dangerous driving, violence, smoking, narcotic use, alcohol consumption and tendency to take risk in sexual behaviors. The respondents express their responses on a five-item scale. The range of responses was from strongly disagree (1) to strongly agree (5). The reliability for dangerous driving, violence, smoking, narcotic use, alcohol consumption, tendency to take risk in sexual behaviors and overall scores of the scale was $0.88,0.77,0.91,0.83,0.93,0.85,0.93$, respectively (34). In the present research, ratability of sub-scales and overall scale using Cronbach alpha for dangerous driving, violence, smoking, narcotic use, alcohol consumption, Hookah smoking, tendency to take risk in sexual behaviors, and overall scores of scale was 0.65, 0.76, 0.94, 0.90, $0.90,0.92,0.89$ and 0.94 , respectively.

\subsubsection{Behavior Activity Profile - Personality Type-A and B Mea-} sure

Behavior activity profile - personality Type-A and B measure of personality developed by Matteson and Ivancevich (35) was used to assess certain types of behavior and thought patterns of high school students' characteristics. The scale consists of 21 bipolar statements and each statement is rated on seven points rating scale scored from seven to one. The best answer for each set of description is the response that most nearly describes the way subject feels, behaves or think. Total scores on these items represent a Global Type-A and B behavior: A score of 122 and above represents Hard-core Type-A, Score range from 99 to 121 reflects Moderate Type - A, 90 to 98 represents Low Type 
- A, 80 to 89 indicates Type X, 70 to 79 indicates Low Type - B, 50 to 69 represents Moderate Type - B, and Score of 40 and below represents Hard-core Type-B. Due to insufficient sample for each type, all patterns of Type A were combined with each other to achieve overall Type A personality pattern and the same was done for Type B. Khan (36) established the reliability of this scale by using the test re-test method. The reliability of total score representing global Type-A behavior was 0.71 . In the current research using alpha Cronbach was equal to 0.56 .

\subsubsection{Type D Personality Pattern Scale - 14 (DS - 14)}

This scale was used to assess NA, SI, and Type D personality (9), the tendency toward negative affectivity (NA) and social inhibition (SI). The NA scale covered dysphoria, worry, and irritability; the SI scale covered discomfort in social interactions, reticence and lack of social poise. Participants rated their personality on a five-point Likert scale ranging from 0 false to 4 true. The NA and SI scales can be scored as continuous variables (range, 0 - 28) to assess these personality traits in their own right. All of the NA and SI items were between 0.62 and 0.82 on their corresponding factor. The reliability of this scale using Cronbach alpha for the NA and SI scales was internally consistent (alpha $=0.88$ and 0.86 ), stable over a three-month period (test-retest $r=0.72$ and 0.82 ) and not dependent on mood and health status. The NA correlated positively with neuroticism $(\mathrm{r}=0.68)$; SI correlated negatively with extraversion ( $r=-0.59$ and - 0.65). In the current research, the validity of this scale using Cronbach alpha for NA was 0.88 , for SI 0.42 and for overall scale of Type D was 0.83 .

\subsubsection{Sensation Seeking Scale (Type T Personality Pattern)}

The sensation seeking scale (SSS) was developed by Zuckerman et al. (37) to assess the personality traits of thrill and adventure seeking, disinhibition, experience seeking and susceptibility to boredom (Type T personality pattern). This scale consists of 40 items using forced - choice format with four sub scales: 1 . Thrill and adventure seeking (TAS): desire to engage in sports or activities involving speed and danger, 2. Disinhibition (Dis): desire for social and sexual disinhibition, 3. Experience seeking (ES): desire for experience through the mind and senses, travel, and a non-conforming lifestyle, 4. Boredom susceptibility (BS): aversion to repetition, routine and dull people. The sensation seeking scale total score was moderately reliable (alpha $=0.75)$, but the subs - scales were only marginally so (between 0.48 and 0.69 ) and only moderately inter-correlated. For the females, the subscales were even less reliable (between 0.44 and 0.67 ) and less intercorrelated (RS was between 0.20 and 0.27 ); even the total score was only marginally reliable (0.68). Significant but small correlation for the Sensation Seeking Scale was obtained for both males $(r=0.19)$ and females $(r=0.28)(38)$.

To analyze the data, Pearson correlation coefficient and multiple stepwise regression using SPSS - 16 were applied.

\section{Results}

To respond to the first question of this research, Pearson correlation was applied and results are given in the below table.

The results of Table 1 shows that risky behavior was negatively correlated with Type D Behavior Pattern $[\mathrm{r}(300)=$ - 0.17, P $<0.01$. Risky behavior was positively correlated with Type A behavior pattern $[\mathrm{r}(218)=-0.225, \mathrm{P}<0.01]$ and Type T Behavior Pattern [r (300) $=0.14, \mathrm{P}<0.05]$. However, no significant correlation was found between risky behavior and Type B Behavior Pattern [r (82) = - 0.195, P> 0.05].

For responding to the second question of the research, multiple stepwise regression was applied and results are given in the below table.

The results of the analyses presented above show that the study model, which includes Type A behavior pattern, Type D behavior pattern, and Type T behavior pattern, explains $11.4 \%$ of the variance in risky behavior. Of these three variables, Type A behavior makes the largest unique contribution (beta $=0.225$ ), although Type D behavior pattern and Type $\mathrm{T}$ behavior pattern made a statistically contribution (beta $=-0.160$, beta $=0.130$ ), respectively. Type $\mathrm{T}$ and Type A personality pattern behavior were positive and type D personality patterns were negative predictors and had a significant role in risky behaviors.

\section{Discussion}

The purpose of the present study was to clarify the role of personality pattern behaviors in risky behaviors in high school students of Chabahar city. The results of this study demonstrated that risky behavior was negatively related to and predicted by Type D behavior pattern. The results of this study are inconsistent with previous researches. The results of previous conducted researches revealed that there was a positive relationship between Type D personality and alcohol dependence in the general population (22). Type D patients were more likely to smoke and to use antidepressants and sleeping pills compared to nonType Ds (21). It seems that type D personality behavior pattern is prone to psychological illness $(21,23)$ leading to drug used and alcohol consumption as a way to decrease their psychological pain. Cultural studies, especially in Japan, demonstrated that Type D personality was four to five times greater risk of psychological distress, and twice 
Table 1. Correlation Coefficient of Risky Behavior and Personality Pattern Behaviors in High School Students of Chabahar City

\begin{tabular}{|c|c|c|c|c|c|}
\hline Variable & Risky Behavior & Type A & Type B & Type D & Type T \\
\hline Risky Behavior & 1.00 & $0.225^{\mathrm{a}}$ & -0.195 & $-0.17^{\mathrm{a}}$ & $0.14^{\mathrm{b}}$ \\
\hline Mean & 106.99 & 98.19 & 67.10 & 32.62 & 61.45 \\
\hline S.D & 40.71 & 13.83 & 15.10 & 9.86 & 4.89 \\
\hline $\mathbf{N}$ & 300 & 218 & 82 & 300 & 300 \\
\hline $\begin{array}{l}\text { Abbreviation: S.D } \\
{ }^{\mathrm{a}} \mathrm{P}<0.01 . \\
{ }^{\mathrm{b}} \mathrm{P}<0.05 .\end{array}$ & & & & & \\
\hline
\end{tabular}

Table 2. Multiple Regression Analysis of Risky Behavior Based on Personality Type Patterns

\begin{tabular}{|c|c|c|c|c|c|c|c|}
\hline Model & $\mathbf{R}$ & $\mathbf{R}^{2}$ & $\Delta \mathbf{R}^{2}$ & B & S.E & $\beta$ & $\mathbf{t}$ \\
\hline Type A & 0.225 & 0.051 & 0.051 & 0.678 & 0.199 & $0.225^{\mathrm{a}}$ & 3.401 \\
\hline Type D & 0.392 & 0.089 & 0.038 & -0.659 & 0.234 & $-0.160^{\mathrm{a}}$ & -2.811 \\
\hline Type T & 0.436 & 0.114 & 0.025 & 1.084 & 0.472 & $0.130^{\mathrm{b}}$ & 2.295 \\
\hline
\end{tabular}

Abbreviations: $\mathrm{R}^{2}$, R Squared, $\Delta \mathrm{R}^{2}$, R Squared Change, S.E, Standard Error

${ }^{\mathrm{a}} \mathrm{P}<0.01$.

${ }^{\mathrm{b}} \mathrm{P}<0.05$

the risk of poor self-rated health and moreover, Type D personality was associated with adverse health status among Japanese elderly people in terms of mental and physical risk (24). For justifying the results of the present study that are incomparable to previous results, the readers should consider the sample of the present research consisted of high school students of Chabahar city thus the cases were adolescents, so they currently had no psychological distress, but may be prone to psychological illness in the future and another reason that the results of this study are not in conformity with the previous research is cultural differences. Iranian culture, especially Chabahar city, is specific and researchers should cautiously generalize their findings and consider these differences.

The results of this study showed that Type A Behavior Pattern positively correlated and predicted the risky of behaviors of high school students. The results of the current study are consistent with the results of previous researches. Type A personality individuals show impulsivity and are impatient to social and environmental demands, especially activities, which require time. Researchers concluded that Type A personality individuals show more dangerous behavior and are at higher behavioral risks. Perry \& Baldwin (14) showed that Type A personalities have more traffic accidents, greater frequency of breaking traffic laws, higher impatience when driving, display greater aggression on the road, and engage in more risky driving behaviors and Type A drivers are more aggressive. Studies demonstrated that Type $\mathrm{A}$ individuals engaged in more high risk behaviors under high stress (15). Type A personality individuals have the tendency to express an aggressive reaction towards violent behavior of others (16). Moreover, Type A individuals exhibit high level of expressed anger and hostility (17). It has been concluded that Type A personality patterns have a sense of competitiveness with others and this type of personality trait increases their aggressive behaviors and hostility toward others, so due to these traits, they are prone to risky behaviors.

Results of the present study illustrated that Type T Behavior Pattern was significantly and positively related to risky behaviors and the findings of this study are in conformity with the results of previous researches; type T personality or sensation seeker have the motives for drinking and they also consume specific types of alcohol (beer, wine and spirits) and have the tendency to engage in risky behaviors associated with alcohol consumption and smoking $(25,27)$. Studies revealed that sensation-seeking peers have direct effect on adolescents' use of both marijuana and alcohol and indirect effect on the use of drugs (26). Driving speed is seen in both males and females with Type T personality, and individuals with high sensation seeking are more likely to engage in speeding while peer sensation seeking levels are predictive of drug use (28). One of the dangerous risky behaviors that Type $\mathrm{T}$ personality or high sensation seekers have is sexual behaviors, and their sexual activities are performed with multiple sexual partners, which means they tend to engage in high risk sexual behaviors (29). It seems that Type T personality or sensation seeking is a pos- 
itive predictor of HIV (30). Type T personalities are more engaged in unprotected sex; studies depicted that sexual sensation seeking also mediated the association between use of drugs other than alcohol and number of sex partners (29). It can be concluded that this type of personality has been recognized as a personality dimension that refers to individual differences in stimulation seeking, excitement seeking, thrill seeking, arousal seeking, and risk taking. Type T personality traits lead to risky behavior and makes individuals prone to risky behaviors.

The result of this study did not find any significant relationship between risky behavior and Type B behavior pattern. The findings of this study are in conformity with the findings of previous researches; Type B individuals engaged in more preventive activities, and fewer risk-related behaviors under high stress, than those who self-reported as Type A (15). Individuals with Type A pattern behavior have the tendency to express assertive reaction when being attacked (16). In conclusion, individuals with Type B personality are easy-going, relaxed individuals and do not exhibit type As' behaviors. moreover, those with type B personality are patients that have no aggression, hostility toward other people and they do not engage in higher riskrelated behaviors under high stress.

\section{Acknowledgments}

We acknowledge the Training and Education Organization of Sistan and Baluchestan and also Chabahar High Schools for their cooperation to fill and collect the questionnaires and scales.

\section{Footnotes}

Authors' Contribution: The study concept and design analysis and interpretation of data was written by Roya Samadypoor and writing discussion and conclusion and drafting of the manuscript was performed by Dr. Bahman Kord Tamini.

Financial Disclosure: The researchers did not receive any financial support from universities, institutions and organizations.

Funding/Support: The findings of this article were extracted from M.A. dissertation of psychology department, University of Sistan and Baluchestan and all rights are reserved.

\section{References}

1. Newman K, Harrison L, Dashiff C, Davies S. Relationships between parenting styles and risk behaviors in adolescent health: an integrative literature review. Rev Lat Am Enfermagem. 2008;16(1):142-50. [PubMed: $18392544]$.
2. Eaton DK, Kann L, Kinchen S, Ross J, Hawkins J, Harris WA, et al. Youth risk behavior surveillance-United States, 2005. MMWR Surveill Summ. 2006;55(5):1-108. [PubMed:16760893].

3. Zadehmohamadi A, Ahmadabadi Z. Considence of high risk behaviors among high schools students in Tehran. J Family Res 2008;4(13):87-100.

4. Dehghan Dehnavi G, Parsamehr M, Naseri S. Cultural capital and high risk behaviors among youth. Int J High Risk Behav Addict. 2014;3(1):17595. doi: 10.5812/ijhrba.17595. [PubMed: 24971301].

5. Kazdin AE. Encyclopedia of Psychology.. Washington DC: APA; 2000.

6. Bernstein DA, Penner L, Clarke-Stewart A, Roy E. Psychology. 8 ed. Boston MA: Houghton Mifflin Company; 2008.

7. Bates KL. Type A personality not linked to heart disease. Michigan University Reccord. 2006;5.

8. Denollet J, Sys SU, Stroobant N, Rombouts H, Gillebert TC, Brutsaert DL. Personality as independent predictor of long-term mortality in patients with coronary heart disease. Lancet. 1996;347(8999):417-21. [PubMed: 8618481].

9. Denollet J. DS14: standard assessment of negative affectivity, social inhibition, and Type D personality. Psychosom Med. 2005;67(1):89-97. doi: 10.1097/01.psy.0000149256.81953.49. [PubMed: 15673629].

10. Kupper N, Pedersen SS, Hofer S, Saner H, Oldridge N, Denollet J. Cross-cultural analysis of type D (distressed) personality in 6222 patients with ischemic heart disease: a study from the International HeartQoL Project. Int J Cardiol. 2013;166(2):327-33. doi: 10.1016/j.ijcard.2011.10.084. [PubMed: 22078395].

11. Lesperance F, Frasure-Smith N. Depression in patients with cardiac disease: a practical review. J Psychosom Res. 2000;48(4-5):379-91. [PubMed: 10880660]

12. Starrenburg AH, Kraaier K, Pedersen SS, van Hout M, Scholten M, van der Palen J. Association of psychiatric history and type D personality with symptoms of anxiety, depression, and health status prior to ICD implantation. Int J Behav Med. 2013;20(3):425-33. doi: 10.1007/s12529012-9244-3. [PubMed: 22821676].

13. Morehouse RE, Farley F, Youngquist JV. Type T personality and the Jungian classification system. J Pers Assess. 1990;54(1-2):231-5. doi: 10.1080/00223891.1990.9673989. [PubMed: 2313544].

14. Perry AR, Baldwin DA. Further evidence of associations of type a personality scores and driving-related attitudes and behaviors. Percept Mot Skills. 2000;91(1):147-54. doi:10.2466/pms.2000.91.1.147.[PubMed: 11011886].

15. Korotkov D, Perunovic M, Claybourn M, Fraser I, Houlihan M, Macdonald $\mathrm{M}$, et al. The type $\mathrm{B}$ behavior pattern as a moderating variable of the relationship between stressor chronicity and health behavior.J Health Psychol. 2011;16(3):397-409. doi:10.1177/1359105310380082. [PubMed: 20978151].

16. Drabek M, Merecz D, Moscicka A. [Trait anxiety and type behavior pattern (A and B) as modifiers of immediate reaction towards violent behaviors]. Med Pr. 2005;56(3):223-34. [PubMed: 16218136].

17. Williams RB. Hostility: Effects on health and the potential for successful behavioral approaches to prevention and treatment. In: Baum A Revenson TA, Singer JE, editors. Handbook of Health Psychology. Mahwah NJ: Erlbaum; 2001. .

18. Catipovic-Veselica K, Amidzic V, Buric D, Ilakovac V, Kozmar $\mathrm{D}$, Durijancek J, et al. Type A/B behavior and eight basic emotions in 1084 employees. Psychol Rep. 1995;76(3 Pt 1):1019-24. doi: 10.2466/pro.1995.76.3.1019. [PubMed: 7568576].

19. Lombardo T, Carreno L. Relationship of type A behavior pattern in smokers to carbon monoxide exposure and smoking topography. Health Psychol. 1987;6(5):445-52. [PubMed: 3678170].

20. Michal M, Wiltink J, Till Y, Wild PS, Munzel T, Blankenberg S, et al. Type-D personality and depersonalization are associated with suicidal ideation in the German general population aged 35-74: results from the Gutenberg Heart Study. J Affect Disord. 2010;125(1-3):227-33. doi:10.1016/j.jad.2010.02.108. [PubMed: 20206385]. 
21. Svansdottir E, van den Broek KC, Karlsson HD, Gudnason T, Denollet J. Type D personality is associated with impaired psychological status and unhealthy lifestyle in Icelandic cardiac patients: a crosssectional study. BMC Public Health. 2012;12:42. doi: 10.1186/1471-2458-1242. [PubMed: 22251667].

22. Bruce G, Curren C, Williams L. Type D personality, alcohol dependence, and drinking motives in the general population.J Stud Alcohol Drugs. 2013;74(1):120-4.

23. Mols F, Oerlemans S, Denollet J, Roukema JA, van de Poll-Franse LV. Type D personality is associated with increased comorbidity burden and health care utilization among 3080 cancer survivors. Gen Hosp Psychiatry. 2012;34(4):352-9. doi: 10.1016/j.genhosppsych.2012.01.014. [PubMed: 22459997].

24. Kasai Y, Suzuki E, Iwase T, Doi H, Takao S. Type D personality is associated with psychological distress and poor self-rated health among the elderly: a population-based study in Japan. PLoS One. 2013;8(10):77918. doi: 10.1371/journal.pone.0077918. [PubMed 24147099].

25. Jones KA, Chryssanthakis A, Groom MJ. Impulsivity and drinking motives predict problem behaviours relating to alcohol use in university students. Addict Behav. 2014;39(1):289-96. doi 10.1016/j.addbeh.2013.10.024. [PubMed: 24176824].

26. Donohew RL, Hoyle RH, Clayton RR, Skinner WF, Colon SE, Rice RE. Sensation seeking and drug use by adolescents and their friends: models for marijuana and alcohol.J Stud Alcohol. 1999;60(5):622-31. [PubMed 10487731].

27. Kraft P, Rise J. The relationship between sensation seeking and smoking, alcohol consumption and sexual behavior among Norwegian adolescents. Health Edu Res. 1994;9(2):193-200.

28. Roberti JW. A review of behavioral and biological correlates of sensation seeking. J Res Pers. 2004;38(3):256-79.
29. McCoul MD, Haslam N. Predicting high risk sexual behaviour in heterosexual and homosexual men: The roles of impulsivity and sensation seeking. Personality and individual differences. 2001;31(8):1303-10.

30. Gullette DL, Lyons MA. Sexual sensation seeking, compulsivity, and HIV risk behaviors in college students. J Community Health Nurs. 2005;22(1):47-60. doi: 10.1207/s15327655jchn2201_5. [PubMed: 15695196].

31. Hampson SE, Tildesley E, Andrews JA, Barckley M, Peterson M. Smoking trajectories across high school: sensation seeking and Hookah use. Nicotine Tob Res. 2013;15(8):1400-8. doi: 10.1093/ntr/nts338. [PubMed: 23322766].

32. Hwang H, Park S. Sensation seeking and smoking behaviors among adolescents in the Republic of Korea. Addict Behav. 2015;45:239-44. doi: 10.1016/j.addbeh.2015.01.041. [PubMed: 25727394].

33. Zadehmohammadi A, Ahmadabadi Z. The co-occurrence of risky behaviors among high school adolescents in Tehran. J Family Res. 2008;4(13):87-100.

34. Zadeh Mohammadi A, Ahmadabadi Z, Heidari M. Construction and assessment of psychometric features of iranian adolescents risktaking scale. Iran J psychiat clinical psychol. 2011;17(3):218-25.

35. Matteson MT, Ivancevich JM. Type A and B behavior patterns and selfreported health symptoms and stress: examining individual and organizational fit. J Occup Med. 1982;24(8):585-9. [PubMed: 7119918].

36. Khan S. A study of role stress, personality type and job burnout on mental and physical health of working women in metropolis. 2015

37. Kolin EA, Price L, Zoob I. Development of a Sensation-Seeking Scale.J Consult Psychol. 1964;28:477-82. [PubMed: 14242306].

38. Ridgeway D, Russell JA. Reliability and validity of the SensationSeeking Scale: Psychometric problems in Form V.JConsult Clin Psychol. 1980;48(5):662. 